\title{
Clinicopathological significance and a potential drug target of $R A R \beta$ in non-small-cell lung carcinoma: a meta-analysis and a systematic review
}

This article was published in the following Dove Press journal:

Drug Design, Development and Therapy

6 April 2016

Number of times this article has been viewed

\author{
Xiaoyun Song* \\ Kang Shi* \\ Shi-Jie Zhou \\ Da-Ping Yu \\ Zhidong Liu \\ Yi Han
}

Department of Thoracic Surgery, Beijing Chest Hospital, Capital Medical University, Beijing, People's Republic of China

*These authors contributed equally to this work

Correspondence: Zhidong Liu; Yi Han Department of Thoracic Surgery, Beijing Chest Hospital, Capital Medical University, No 97, Machang, Tongzhou District, Beijing I0I149, People's Republic of China Email zhidongliu66@yahoo.com; hanyi588@yahoo.com
Abstract: Lung cancer is the leading cause of cancer-related mortality in men worldwide. Aberrant $R A R \beta$ promoter methylation has been frequently investigated in non-small-cell lung carcinoma (NSCLC), the most common form of lung cancer. The aim of present study was to carry out a meta-analysis and a systematic review to evaluate clinicopathological significance of $R A R \beta$ promoter hypermethylation in NSCLC. A systematic literature search was carried out. The data were extracted and assessed by two reviewers independently. The Cochrane software Review Manager 5.2 was used to conduct the review. Odds ratios (ORs) with 95\% corresponding confidence intervals (CIs) were calculated. A total of 18 relevant articles were available for meta-analysis which included 1,871 participants. The frequency of $R A R \beta$ hypermethylation was significantly increased in NSCLC than in nonmalignant lung tissue, and the pooled OR was 5.69 $(P<0.00001)$. RAR $\beta$ hypermethylation was significantly more frequently observed in adenocarcinoma (AC) than in squamous cell carcinoma (SCC), and the pooled OR was $1.47(P=0.005)$. Hypermethylation of $R A R \beta$ gene in NSCLC was 2.46 times higher in smoking than in nonsmoking individuals, and the pooled OR was $2.46(P=0.0002) . R A R \beta$ hypermethylation rate was not significantly correlated with stage of the disease and sex. $R A R \beta$ gene methylation status was not associated with prognosis of patients with NSCLC. In conclusion, $R A R \beta$ promoter hypermethylation significantly increased in NSCLC than in non-neoplastic lung tissue and is predominant in $\mathrm{AC}$, suggesting that $R A R \beta$ methylation contributes to the development of NSCLC, especially AC. $R A R \beta$ gene is a potential novel target for development of personalized therapy in patients with NSCLC, and is promising in restoration of retinoic acid-target gene induction via demethylation of $R A R \beta 1^{\prime}$ promoter.

Keywords: NSCLC, RAR $\beta$, methylation, tumor suppressor gene, drug target, RA-resistance, meta-analysis, odds ratio

\section{Introduction}

Lung cancer is the leading cause of cancer-related mortality in men worldwide. ${ }^{1}$ Lung cancers can be classified into two major histological groups: small-cell-lung carcinoma and non-small-cell lung carcinoma (NSCLC). NSCLC consists of adenocarcinoma (AC), squamous cell carcinoma (SCC), large cell carcinoma, and others. ${ }^{2}$ NSCLC is the most common form, and although the advent of targeted therapies has improved outcomes in a subset of patients, the overall 5-year survival rate remains less than $15 \% .{ }^{3}$ It is critical to identify a molecular predictive marker for monitoring its progression and prognosis. Aberrant DNA methylation is a commonly observed epigenetic modification in human malignancies including NSCLC. Hypermethylation in promoter regions of many tumor suppressor genes inactivates gene transcription and contributes 
to the development and progression of various cancers by abolishing tumor suppressor gene function. ${ }^{4-6}$ Currently, many genes were identified as tumor-specifically methylated by using a genome-wide approach to investigate $\mathrm{CpG}$ island methylation in a large number of NSCLC patients. Approximately, half of the methylated genes are involved in the regulation of gene expression and cell adhesion, and some of them could be prognostic markers. ${ }^{7,8}$ Retinoic acid (RA) and its derivatives (retinoids) are required for normal lung development, cell growth, and differentiation, and a deficiency in RA is a risk factor for the development of lung cancer. ${ }^{9-12}$ RA activity is mediated primarily by retinoic acid receptors (RAR), including $\operatorname{RAR} \alpha, \operatorname{RAR} \beta$, and $\operatorname{RAR} \gamma$, which belong to the nuclear receptor superfamily of transcription factors. $R A R \beta$ gene is located at chromosome $3 \mathrm{p} 24$, a region frequently deleted in lung cancer. Loss of expression of $R A R \beta$ during cancer development is associated with tumorigenesis and retinoid resistance; induction of its expression, on the other hand, can suppress carcinogenesis. ${ }^{13}$ Previous studies have reported that $R A R \beta$ hypermethylation was frequently observed in NSCLC tissue, but the reported rates of $R A R \beta$ hypermethylation in NSCLC were remarkably diverse due to smaller number of patients. In addition, several studies have revealed an association between DNA methylation and tobacco carcinogens in animal models as well as in NSCLC patients, but the results were inconsistent. ${ }^{14-18}$ In the present study, we systematically reviewed the studies of $R A R \beta$ promoter hypermethylation in the process of NSCLC onset and progression, and quantified the association between $R A R \beta$ promoter hypermethylation and the NSCLC by using metaanalysis methods. In addition, we analyzed the relationship of $R A R \beta$ promoter hypermethylation with clinical features in NSCLC patients and discussed the tumor suppressor function, RA resistance, as well as the clinical significance of $R A R \beta$ in NSCLC.

\section{Materials and methods Search strategy}

We conducted a literature search for articles from the earliest data to August 2015 in PubMed, EMBASE, and Web of Science using the search terms: "lung" and "cancer or tumor or neoplasm or carcinoma", "methylation", and " $R A R \beta$ or retinoic acid receptor- $\beta$ ". We also screened manually the reference lists of retrieved articles for additional articles. There were 150 articles identified from PubMed, 67 articles from EMBASE, and 340 articles from Web of Science. A total of 557 articles were screened by article titles and abstracts.

\section{Selection criteria}

Studies were selected based on the following inclusion criteria: 1) studies that reported the relationship between $R A R \beta$ hypermethylation and NSCLC clinicopathological parameters and prognosis; 2) $R A R \beta$ hypermethylation evaluated in the primary NSCLC tissues; 3) $R A R \beta$ hypermethylation examined by methylation-specific polymerase chain reaction (MSP); and 4) studies provided sufficient information to estimate hazard ratio (HR) about overall survival (OS) and 95\% confidence interval (CI). The exclusion criteria included the following: 1) reviews, letters, case reports, expert opinion, conference abstracts, editorials; 2) all publications regarding in vitro/ex vivo studies, cell lines, and human xenografts; 3) studies in which RAR $\beta$ protein expression was investigated, and $R A R \beta$ hypermethylation was not reported; and 4) studies in which same population or overlapping data were used.

Although our search did not have language limits initially, for the full-text reading and final evaluation we only performed the review of the studies published in English language. After exclusion of nonrelevant and/or redundant publications from different databases, the 44 remaining papers were evaluated in the full-text version for inclusion and exclusion criteria.

\section{Data extraction and methodological assessment}

Two authors (XS, KS) independently reviewed and extracted data from eligible studies. Disagreements were resolved by discussion and consensus. If they could not reach a consensus, a third author (SZ) was consulted. The following information was recorded for each study: the first author name, year of publication, sample source, number of cases, clinicopathological parameters, cancer tumor node metastasis stage, methylation detection method, and methylation rate and site. Data for study characteristics and clinical responses were summarized and organized into a table format. Heterogeneity of investigation was evaluated to determine whether or not the data of the various studies could be analyzed for meta-analysis.

For the methodological evaluation of the studies, three investigators (DPY, ZL, and YH) read through each publication independently, and they assessed and scored them according to the Newcastle Ottawa Quality Assessment Scale (NOQAS). The three readers provided the quality scores and compared them, and then they reached a consensus value for each item. Those scales allocate a maximum of nine points 
for the quality of selection, comparability, exposure, and outcomes for study participants. The Newcastle-Ottawa scale scores ranged from 0 to 9 , and a study with a score of 7 or more indicates a good quality.

\section{Statistical analysis}

The meta-analysis was conducted using Review Manager 5.2 (Cochrane Collaboration, Software Update, Oxford, UK). Odds ratios (ORs) with its 95\% CIs were calculated. The assessment of statistical heterogeneity was done by using the Cochran's $Q$ statistic and $I^{2}$ tests. When the $I^{2}$ value was below $50 \%$, a fixed effect model was used, and when the $I^{2}$ value was $50 \%$ or greater, a random effect model was used. We also explored reasons for statistical heterogeneity using sensitivity analysis. The pooled frequency of $R A R \beta$ hypermethylation and $95 \%$ CIs were estimated. The frequency of $R A R \beta$ hypermethylation was compared in different tumor characteristics. The pooled OR was estimated for the association between $R A R \beta$ hypermethylation and clinicopathological features. $P$-values tailed less than 0.05 were considered statistically significant. Publication bias was assessed by using a method reported by Egger et al. ${ }^{19}$

\section{Results \\ Identification of relevant studies and study quality}

Eighteen articles published from 2004 to 2014 were eligible for this meta-analysis, as shown in Figure 1. The quality of included articles was assessed by using NOQAS. Those scales allocate a maximum of 9 points for the quality of selection, comparability, exposure, and outcomes for study participants. The NOS scores ranged from 0 to 9 , and a study with a score of 7 or more indicates a good quality. Among those studies, six scored 9 points, nine scored 8 points, and three scored 7 points. Hence, the studies were of a relatively high quality (data not shown).

\section{Study characteristics}

A total of 1,871 NSCLC patients from the People's Republic of China, Japan, Korea, Finland, Australia, and the USA

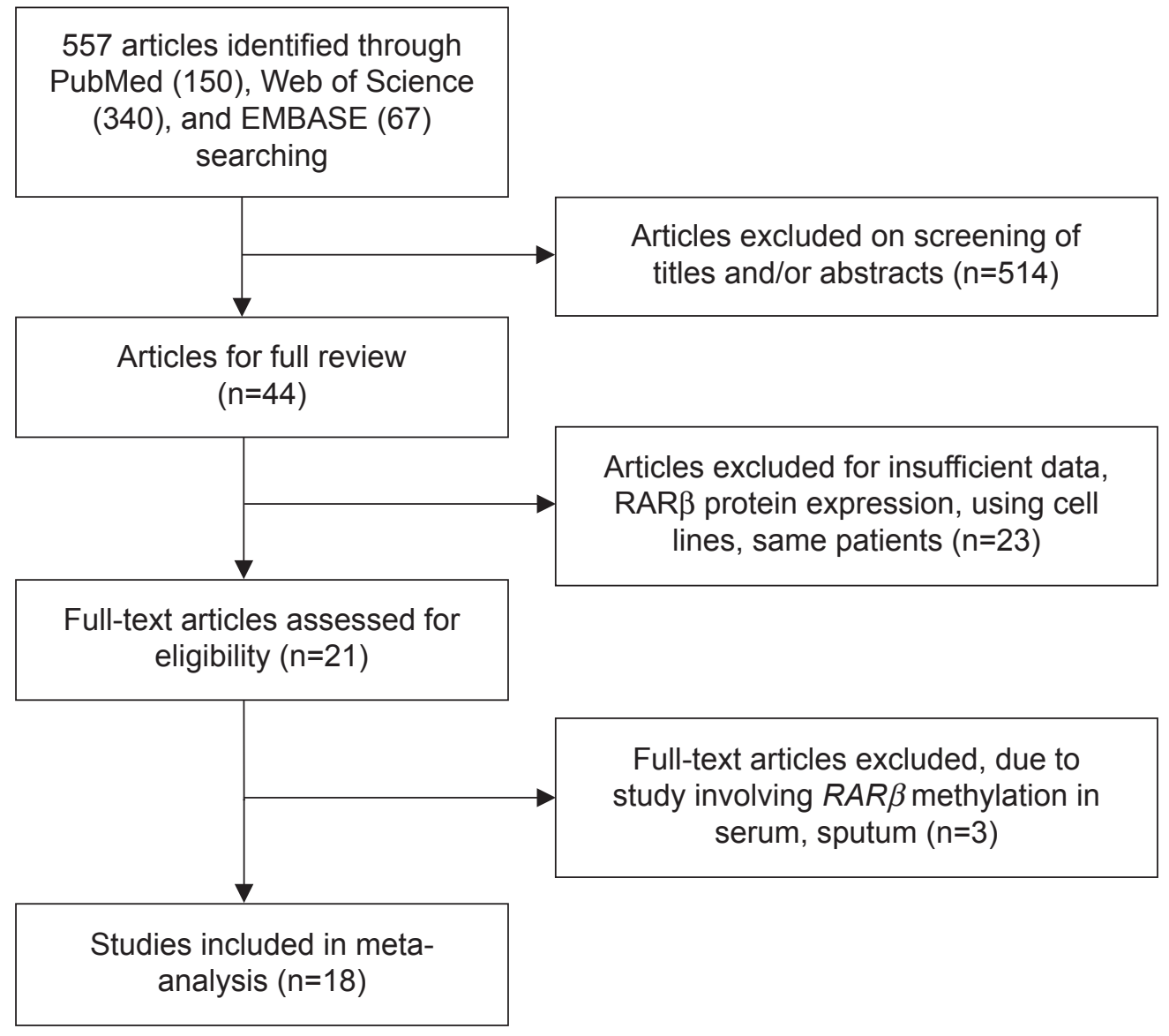

Figure I Schematic flow diagram for selection of included studies. 
Table I Main characteristics of included studies

\begin{tabular}{|c|c|c|c|c|c|c|c|c|}
\hline Author & Year & Country & $\begin{array}{l}\text { Sex } \\
(F / M)\end{array}$ & $\begin{array}{l}\text { Histology } \\
\text { (AC/SCC) }\end{array}$ & $\begin{array}{l}\text { Stage } \\
\text { (low/advanced) }\end{array}$ & $\begin{array}{l}\text { Smoking } \\
(-I+)\end{array}$ & Methods & $\begin{array}{l}\text { Methylation } \\
\text { site }\end{array}$ \\
\hline Li et $\mathrm{al}^{44}$ & 2014 & People's Republic of China & $63 / 104$ & $81 / 86$ & $102 / 65$ & $69 / 44$ & MSP & Promoter \\
\hline Zhao et $\mathrm{a}^{45}$ & 2012 & People's Republic of China & $12 / 68$ & $35 / 45$ & $50 / 30$ & $19 / 61$ & MSP & Promoter \\
\hline Zhang et $\mathrm{a}^{46}$ & 2011 & People's Republic of China & NA & NA & NA & NA & MSP & Promoter \\
\hline Li et al ${ }^{40}$ & 2014 & People's Republic of China & NA & $10 / 29$ & $34 / 22$ & NA & MSP & Promoter \\
\hline Scesnaite et $\mathrm{al}^{47}$ & 2012 & Finland & $83 / 129$ & $103 / 79$ & $35 / 71$ & $2 / 104$ & MSP & Promoter \\
\hline Yanagawa et al ${ }^{18}$ & 2011 & Japan & $41 / 69$ & NA & $44 / 18$ & $26 / 36$ & MSP & Promoter \\
\hline Liu et $\mathrm{a}^{48}$ & 2010 & People's Republic of China & $21 / 59$ & $22 / 37$ & $60 / 20$ & $33 / 47$ & MSP & Promoter \\
\hline Hawes et al ${ }^{49}$ & 2010 & USA & $45 / 72$ & $51 / 59$ & $93 / 24$ & $5 / 112$ & $\begin{array}{l}\text { Methy } \\
\text { light }\end{array}$ & Promoter \\
\hline Kubo et $\mathrm{a}^{50}$ & 2009 & Japan & $62 / 38$ & NA & $52 / 48$ & $70 / 30$ & MSP & Promoter \\
\hline Umemura et $\mathrm{a}^{33}$ & 2008 & Japan & $1 / 10$ & $6 / 4$ & $5 / 6$ & $2 / 9$ & MSP & promoter \\
\hline Seng et $\mathrm{al}^{51}$ & 2008 & Australia & $84 / 155$ & $146 / 92$ & $86 / 153$ & NA & MSP & promoter \\
\hline Hsu et $\mathrm{al}^{52}$ & 2007 & People's Republic of China & NA & $33 / 37$ & $48 / 31$ & $18 / 56$ & MSP & promoter \\
\hline Yanagawa et a $\left.\right|^{134}$ & 2007 & Japan & $29 / 72$ & $62 / 39$ & $33 / 68$ & $26 / 36$ & MSP & promoter \\
\hline Katayama et al ${ }^{53}$ & 2007 & Japan & $10 / 24$ & $32 / 1$ & $0 / 34$ & NA & MSP & promoter \\
\hline Kim et a ${ }^{39}$ & 2005 & Korea & NA & NA & NA & NA & MSP & promoter \\
\hline Kim et $\mathrm{al}^{43}$ & 2005 & Korea & NA & $42 / 27$ & $31 / 30$ & NA & MSP & promoter \\
\hline Tomizawa et al ${ }^{17}$ & 2004 & Japan & $43 / 77$ & $45 / 72$ & $32 / 86$ & $29 / 61$ & MSP & Promoter \\
\hline Topaloglu et al ${ }^{54}$ & 2004 & USA & NA & $21 / 7$ & $26 / 5$ & NA & $\begin{array}{l}\text { Real-time } \\
\text { PCR }\end{array}$ & Promoter \\
\hline
\end{tabular}

Abbreviations: F, female; M, male; AC, adenocarcinoma; SCC, squamous cell carcinoma; MSP, methylation-specific PCR; PCR, polymerase chain reaction; NA, not available.

were enrolled. The variables from 18 relevant studies are listed in Table 1.

\section{The correlation of $R A R \beta$ hypermethylation with clinicopathological features}

The frequency of $R A R \beta$ hypermethylation was significantly increased in NSCLC than in nonmalignant lung tissue, and the pooled OR was 5.69 with $95 \%$ CI: $3.32-9.76, z=6.32$, $P<0.00001$ (Figure 2). $R A R \beta$ hypermethylation was significantly more frequently observed in AC than in SCC, and the pooled OR was 1.47 with $95 \%$ CI: $1.12-1.93, z=2.79$, $P=0.005$ (Figure 3). $R A R \beta$ hypermethylation rate was not significantly correlated with stage of the disease, and the pooled OR was 0.82 with $95 \%$ CI: $0.63-1.08, z=1.4, P=0.16$ (Figure 4). RAR $\beta$ methylation was 2.46 times higher in smoking than in nonsmoking individuals, and the pooled OR was 2.46 with $95 \%$ CI: $1.54-3.93, z=3.76, P=0.0002$ (Figure 5). $R A R \beta$ gene hypermethylation had no correlation with patient sex, and the pooled OR was 1.20 with $95 \% \mathrm{CI}$ : $0.79-1.84, z=0.85, P=0.40$ (Figure 6). $R A R \beta$ gene methylation status was not associated with prognosis of patients with NSCLC, the pooled HR was 1.05 with $95 \%$ CI: $0.68-1.64$, $z=0.23, P=0.82$ (Figure 7).

\section{Sensitivity analyses and publication bias}

A sensitivity analysis was conducted by removing one study from the meta-analysis at a time, and the overall results were not significantly affected. The pooled ORs or HRs were not significantly changed, indicating the stability of our analyses. The funnel plots were largely symmetric (Figure 8A-F), suggesting there were no significant publication biases in the meta-analysis of $R A R \beta$ hypermethylation and clinicopathological features.

\section{Discussion}

The human $R A R \beta$ gene is located on chromosome 3 , locus $3 \mathrm{p} 24$, and consists of five distinct isoforms: hRAR $\beta 1^{\prime}$, hRAR $\beta 1$, hRAR $\beta 2$, hRAR $\beta 4$, and hRAR $\beta 5 .{ }^{20,21}$ Among those five isoforms, hRAR $\beta 1$ and hRAR $\beta 2$ are the functional isoforms that activate distinct cassettes of target genes with different biological effects. ${ }^{22}$ hRAR $\beta 1$ is a fetal isoform, which may play an important role during development in human. ${ }^{23}$ The hRAR $\beta 1^{\prime}$ was identified in normal lung tissue and bronchial epithelial cells. The absence of hRAR $\beta 1^{\prime}$ is associated with retinoid resistance in human lung carcinogenesis..$^{24,25}$ The reexpression of hRAR $\beta 1^{\prime}$ in lung cancer cells restored RA-target gene induction and growth suppression following retinoid treatment. ${ }^{25}$ The hRAR $\beta 2$ is the retinoid-inducible splicing isoform, and multiple hRAR $\beta 2$ transcript variants are expressed in both normal and neoplastic cells. ${ }^{26,27}$ Both the hRAR $\beta 1^{\prime}$ and hRAR $\beta 2$ transcripts are obtained from the transcription start sites of $\mathrm{P} 2$ promote which contains a $\mathrm{CpG}$-rich region that is susceptible to methylation-induced silencing. ${ }^{28-31}$ 


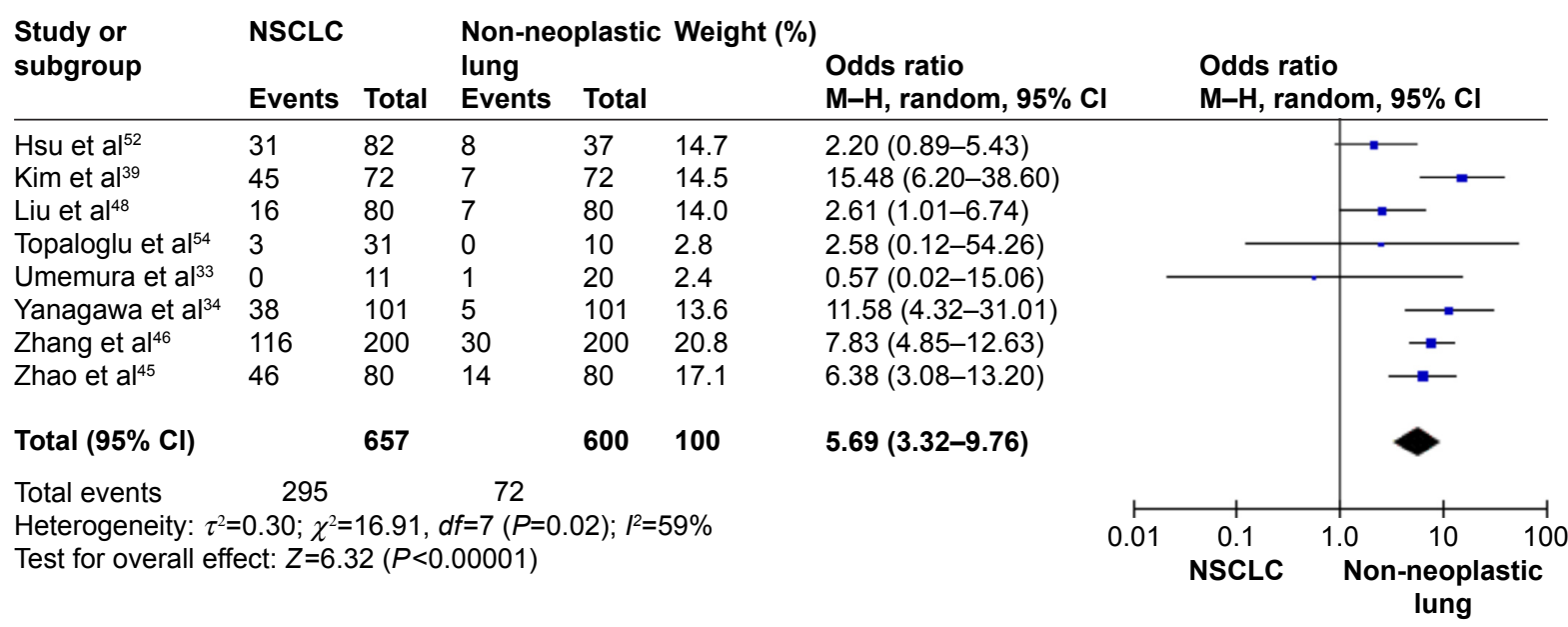

Figure 2 Forest plot for RAR $\beta$ hypermethylation in NSCLC and non-neoplastic lung tissue.

Abbreviations: NSCLC, non-small-cell lung carcinoma; Cl, confidence interval; df, degree of freedom; M-H, Mantel-Haenszel.



Figure 3 Forest plot for RAR $\beta$ hypermethylation in AC and SCC.

Abbreviations: $\mathrm{AC}$, adenocarcinoma; $\mathrm{SCC}$, squamous cell carcinoma; $\mathrm{Cl}$, confidence interval; df, degree of freedom; $\mathrm{M}-\mathrm{H}$, Mantel-Haenszel.

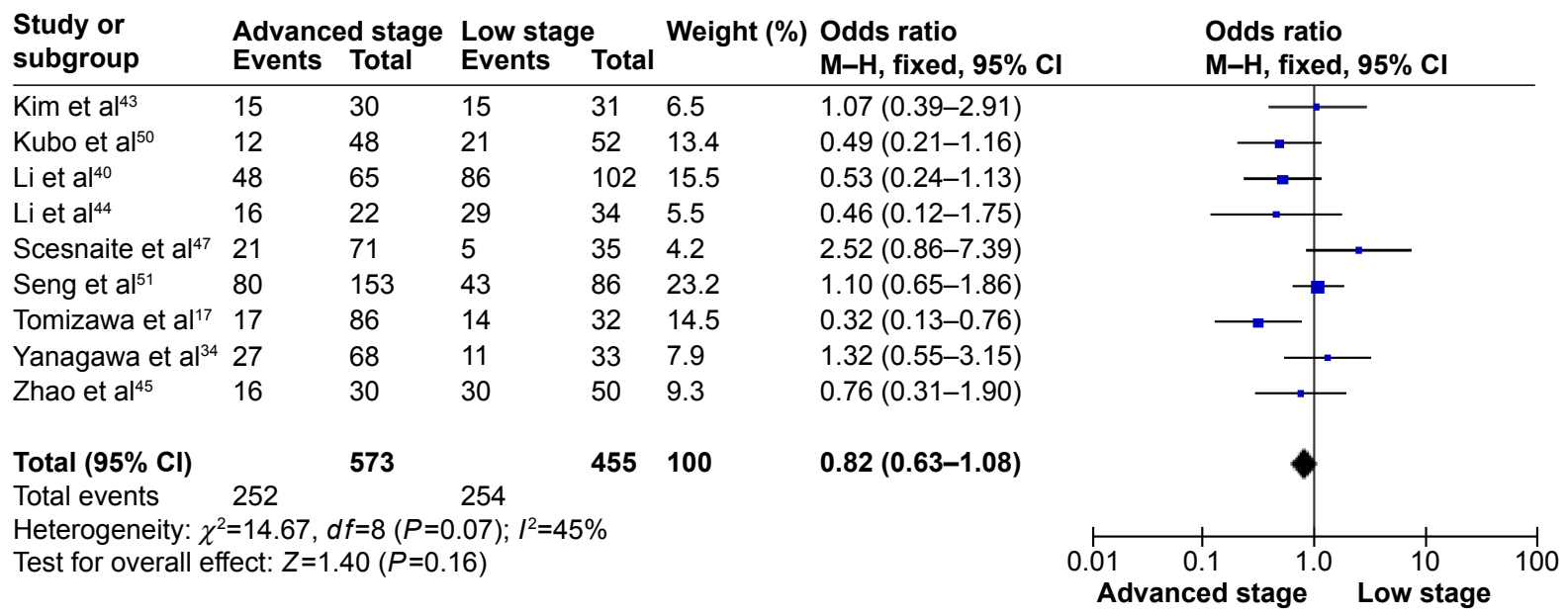

Figure 4 Forest plot for RAR $\beta$ hypermethylation in advanced and low stage of NSCLC.

Abbreviations: NSCLC, non-small-cell lung carcinoma; Cl, confidence interval; $d f$, degree of freedom; M-H, Mantel-Haenszel. 


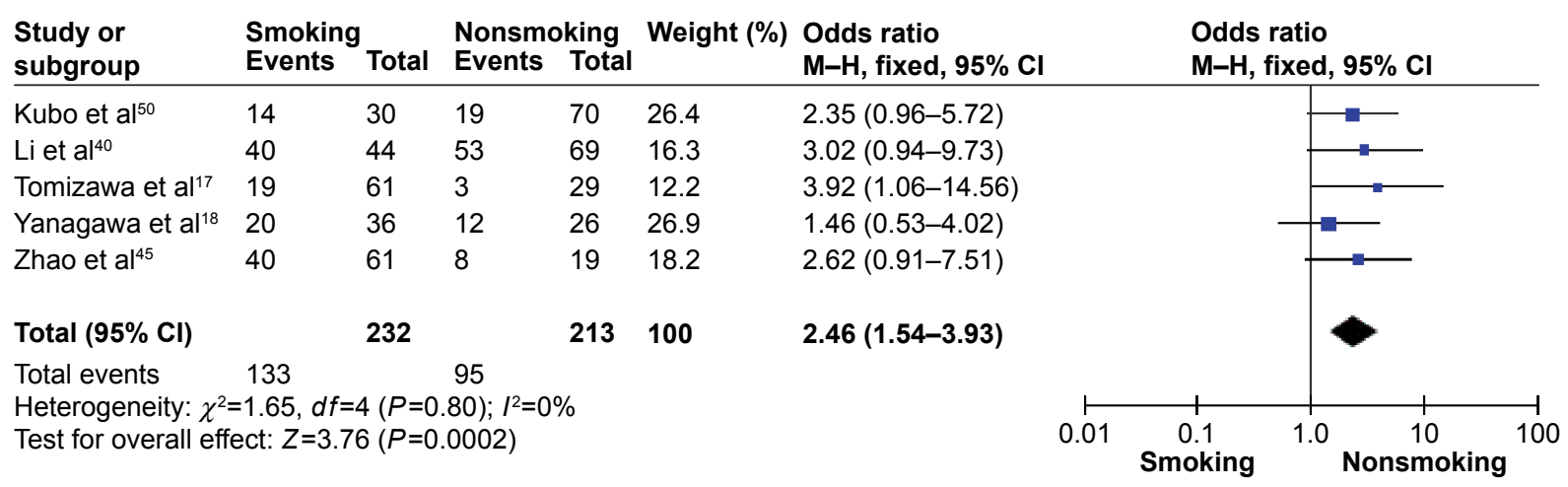

Figure 5 Forest plot for RAR $\beta$ hypermethylation of NSCLC in smoking and nonsmoking individual.

Abbreviations: NSCLC, non-small-cell lung carcinoma; $\mathrm{Cl}$, confidence interval; $d f$, degree of freedom; $\mathrm{M}-\mathrm{H}$, Mantel-Haenszel.

Aberrant methylation of the promoter regions of genes is a major mechanism of gene silencing in tumor. ${ }^{32} \mathrm{~A}$ number of studies reported that $R A R \beta$ promoter hypermethylation was observed in NSCLC, but the rate was remarkably diverse due to small power. ${ }^{33,34}$ In the present study, we conducted a metaanalysis and pooled 18 studies which included 1,871 NSCLC patients. Our data showed $R A R \beta$ promoter hypermethylation significantly increased by 5.69 times in NSCLC than in nonneoplastic lung tissue, indicating that $R A R \beta$ promoter hypermethylation contributed to the initiation and development of NSCLC. On the other hand, the translation of hRAR $\beta 1^{\prime}$ initiates at the $\mathrm{P} 2$ promoter, and $R A R \beta$ promoter hypermethylation suppresses $\mathrm{hRAR} \beta 1^{\prime}$ expression that is required for RA-target gene induction. Therefore, $R A R \beta$ promoter hypermethylation could lead to the incident of retinoid resistance following retinoid treatment. Confirmation studies need to be carried out in future. $R A R \beta$ promoter hypermethylation is a reversible event; drug treatment through demethylation may be used not only to delay carcinogenesis and the progression of NSCLC, but also to restore RA-target gene induction. Virmani et al demonstrated that the treatment of lung cancer cell lines with demethylation agent 5 -aza-2'-deoxycytidine (5-AZA-CdR) can restore $R A R \beta$ expression. ${ }^{32}$ A Phase I/II trial in patients with stage IV NSCLC suggests that 5-AZA$\mathrm{CdR}$ may have some clinical activity against metastatic NSCLC. ${ }^{35}$ Recently, curcumin, a potent cancer preventive agent, ${ }^{36}$ was also reported to significantly decrease $R A R \beta$ promoter methylation and elevate $R A R \beta$ expression at the messenger RNA and protein levels in lung cancer A549 and H460 cells. ${ }^{37}$ Taken together, demethylation of $R A R \beta$ promoter could suppress the development of NSCLC, and potentially restores RA-target gene induction. $R A R \beta$ is a promising gene target for the development of personalized therapy in patients with NSCLC.

Hua et al conducted a meta-analysis and reported that the frequency of $R A R \beta$ promoter hypermethylation increased in

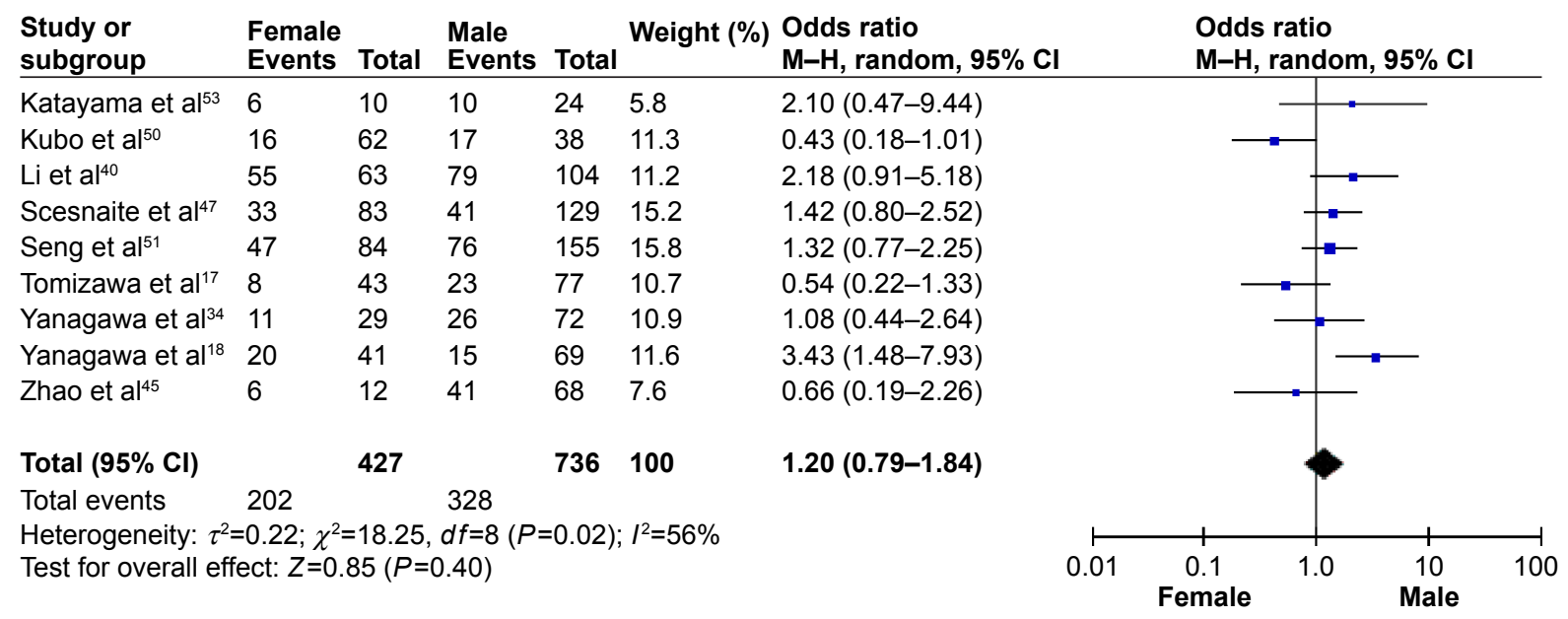

Figure 6 Forest plot for RAR $\beta$ hypermethylation of NSCLC in different sexes.

Abbreviations: NSCLC, non-small-cell lung carcinoma; $\mathrm{Cl}$, confidence interval; $\mathrm{df}$, degree of freedom; $\mathrm{M}-\mathrm{H}$, Mantel-Haenszel. 


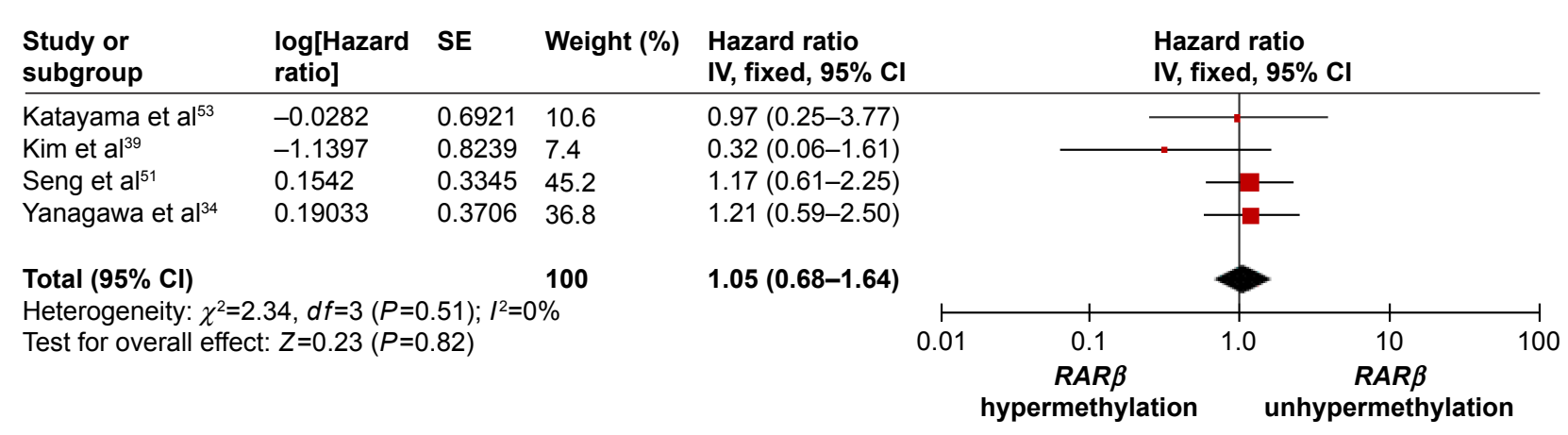

Figure 7 Forest plot for the association between RAR $\beta$ hypermethylation and risk of NSCLC.

Abbreviations: NSCLC, non-small-cell lung carcinoma; $\mathrm{Cl}$, confidence interval; $d f$, degree of freedom; $\mathrm{SE}$, standard error of the mean.
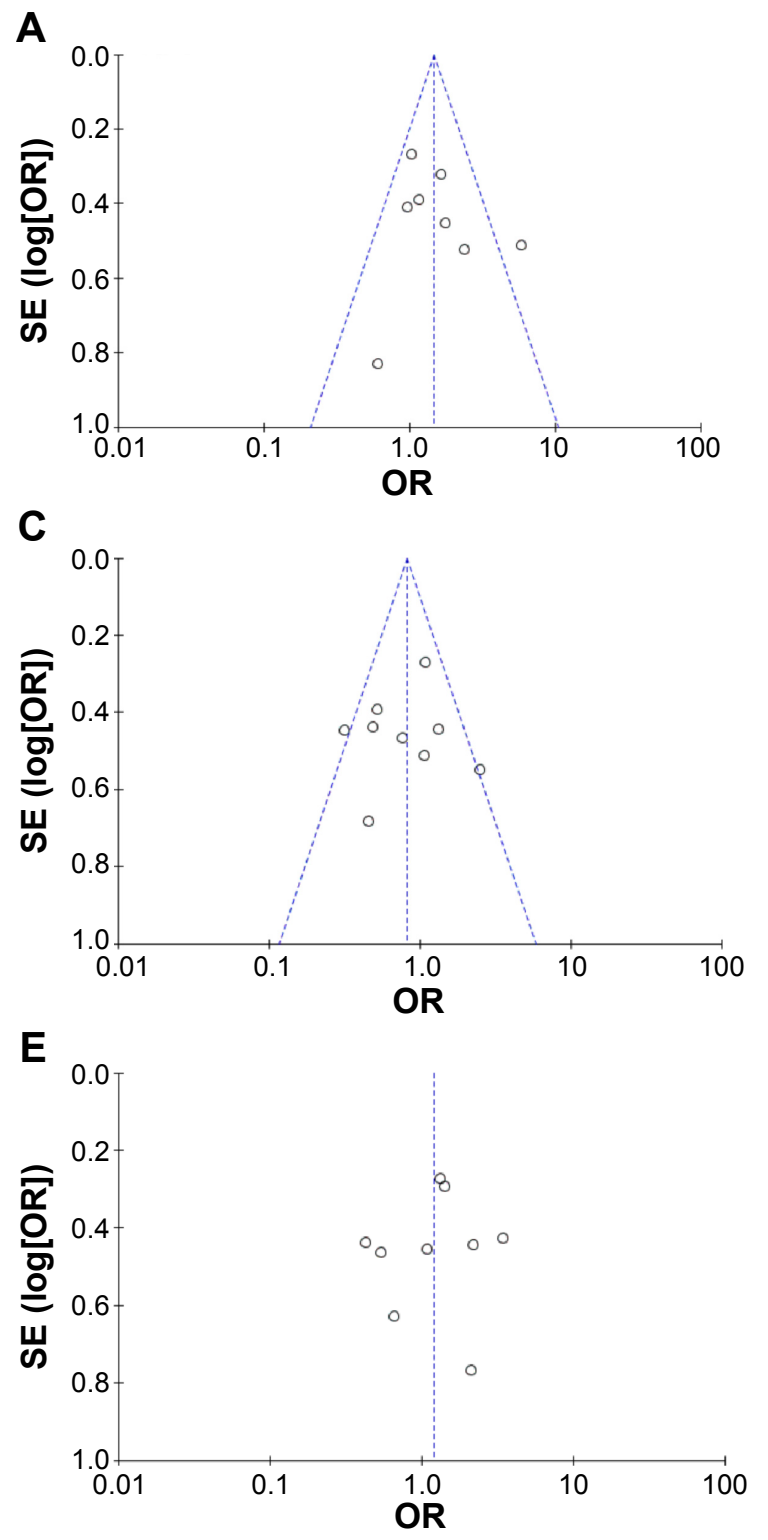
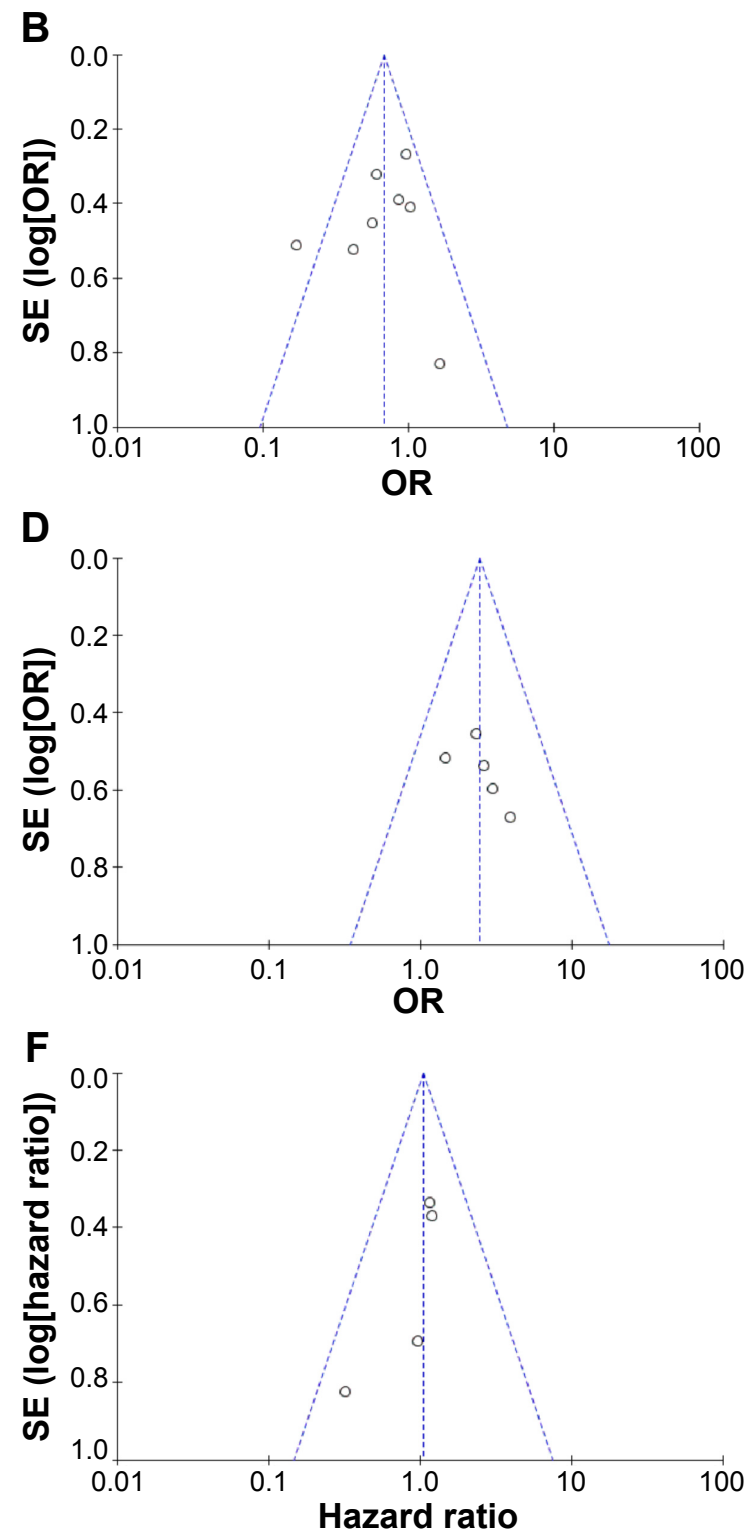

Figure 8 Funnel plot for publication bias.

Notes: (A) RAR $\beta$ hypermethylation in NSCLC and non-neoplastic lung tissue; (B) RAR $\beta$ hypermethylation in AC and SCC; (C) RAR $\beta$ hypermethylation in advanced and low stage of NSCLC; (D) RAR $\beta$ hypermethylation of NSCLC in smoking and nonsmoking individual; (E) RAR $\beta$ hypermethylation of NSCLC in different sexes; (F) the association between RAR $\beta$ hypermethylation and the risk of NSCLC.

Abbreviations: NSCLC, non-small-cell lung carcinoma; AC, adenocarcinoma; SCC, squamous cell carcinoma; SE, standard error of the mean; OR, odds ratio; df, degree of freedom. 
NSCLC than autologous controls, suggesting the methylation status could be a valuable diagnostic tool for NSCLC. ${ }^{38}$ However, they only accessed eleven studies. Our analysis included additional seven studies and showed more convincing results. In addition, we also found that the rate of $R A R \beta$ hypermethylation was increased in AC than SCC and that there was a strong correlation between methylation status of $R A R \beta$ and smoking in patients with NSCLC.

The rate of $R A R \beta$ hypermethylation between $\mathrm{AC}$ and SCC has been compared in previous studies and the results were contradictory as the studies included limited number of patients. ${ }^{39,40}$ We pooled eight studies and analyzed the frequency of $R A R \beta$ promoter hypermethylation in $\mathrm{AC}$ and SCC. The rate of $R A R \beta$ promoter hypermethylation was higher in AC than SCC, suggesting that the molecular mechanisms could be different between AC and SCC. Additionally, $R A R \beta$ promoter hypermethylation significantly increased in smoking NSCLC patients compared to nonsmoking NSCLC patients, indicating that smoking induced gene methylation which may lead to malignant growth and cancer development. ${ }^{41,42}$

Several studies reported the correlation between methylation status of $R A R \beta$ and survival in NSCLC patients, and the results were inconsistent. ${ }^{34,43}$ In the present meta-analysis, no significant association between $R A R \beta$ promoter methylation status and survival was found. Additionally, the rate of $R A R \beta$ promoter hypermethylation was similar between lower and advanced stages of disease. Our study only included the articles published in English or Chinese language, and did not select some relevant papers published in other languages, which may result in certain publication bias. Hence, cautions should be taken when our findings are interpreted among the general populations.

\section{Conclusion}

In summary, $R A R \beta$ promoter hypermethylation significantly increased in NSCLC tumor than in non-neoplastic lung tissue, suggesting that $R A R \beta$ methylation contributes to the development of NSCLC. RAR $\beta$ gene is a potential novel target for demethylation treatment in patients with NSCLC, and is promising in restoration of RA-target gene induction via demethylation of $R A R \beta 1^{\prime}$ promoter. $R A R \beta$ promoter hypermethylation is associated with smoking behavior as well as histologic subtypes of NSCLC in patients with NSCLC. The rate of $R A R \beta$ promoter hypermethylation is higher in $\mathrm{AC}$ than SCC. $R A R \beta$ methylation status is not correlated to survival of patients with NSCLC.

\section{Acknowledgment}

This work was not supported by any fund. This work did not get contribution from other people except authors.

\section{Author contributions}

All authors contributed toward data analysis, drafting and critically revising the paper and agree to be accountable for all aspects of the work.

\section{Disclosure}

The authors report no conflicts of interest in this work.

\section{References}

1. Jemal A, Siegel R, Xu J, Ward E. Cancer statistics, 2010. CA Cancer J Clin. 2010;60:277-300. doi:10.3322/caac.20073 caac.20073 [pii].

2. Travis WD. Pathology of lung cancer. Clin Chest Med. 2011;32:669-692. doi:10.1016/j.ccm.2011.08.005 S0272-5231(11)00080-3 [pii].

3. Tsai MF, Wang CC, Chen JJ. Tumour suppressor HLJ1: a potential diagnostic, preventive and therapeutic target in non-small cell lung cancer. World J Clin Oncol. 2014;5:865-873. doi:10.5306/wjco.v5.i5.865.

4. Baylin SB, Herman JG, Graff JR, Vertino PM, Issa JP. Alterations in DNA methylation: a fundamental aspect of neoplasia. Adv Cancer Res. 1998;72:141-196.

5. Baylin SB, Esteller M, Rountree MR, Bachman KE, Schuebel K, Herman JG. Aberrant patterns of DNA methylation, chromatin formation and gene expression in cancer. Hum Mol Genet. 2001;10: 687-692.

6. Merlo A, Herman JG, Mao L, et al. $5^{\prime}$ CpG island methylation is associated with transcriptional silencing of the tumour suppressor p16/CDKN2/MTS1 in human cancers. Nat Med. 1995;1:686-692.

7. Heller G, Babinsky VN, Ziegler B, et al. Genome-wide CpG island methylation analyses in non-small cell lung cancer patients. Carcinogenesis. 2013;34:513-521. doi:10.1093/carcin/bgs363.

8. Sandoval J, Mendez-Gonzalez J, Nadal E, et al. A prognostic DNA methylation signature for stage I non-small-cell lung cancer. J Clin Oncol. 2013;31:4140-4147. doi:10.1200/JCO.2012.48.5516.

9. Grummer MA, Thet LA, Zachman RD. Expression of retinoic acid receptor genes in fetal and newborn rat lung. Pediatr Pulmonol. 1994; 17:234-238.

10. Mendelsohn C, Lohnes D, Décimo D, et al. Function of the retinoic acid receptors (RARs) during development (II). Multiple abnormalities at various stages of organogenesis in RAR double mutants. Development. 1994;120:2749-2771.

11. Chytil F. Retinoids in lung development. FASEB J. 1996;10: 986-992.

12. Minna JD, Mangelsdorf DJ. Retinoic acid receptor expression abnormalities in lung cancer: important clues or major obstacles? J Natl Cancer Inst. 1997;89:602-604.

13. Bogos K, Renyi-Vamos F, Kovacs G, Tovari J, Dome B. Role of retinoic receptors in lung carcinogenesis. J Exp Clin Cancer Res. 2008;27:18. doi:10.1186/1756-9966-27-18 1756-9966-27-18 [pii].

14. Lee YW, Klein CB, Kargacin B, et al. Carcinogenic nickel silences gene expression by chromatin condensation and DNA methylation: a new model for epigenetic carcinogens. Mol Cell Biol. 1995;15:2547-2557.

15. Swafford DS, Middleton SK, Palmisano WA, et al. Frequent aberrant methylation of 16INK4a in primary rat lung tumors. Mol Cell Biol. 1997; 17:1366-1374.

16. Rom WN, Hay JG, Lee TC, Jiang Y, Tchou-Wong KM. Molecular and genetic aspects of lung cancer. Am J Respir Crit Care Med. 2000; 161:1355-1367. doi:10.1164/ajrccm.161.4.9908012.

17. Tomizawa $Y$, Iijima $H$, Nomoto $T$, et al. Clinicopathological significance of aberrant methylation of RARbeta2 at 3p24, RASSF1A at 3p21.3, and FHIT at 3p14.2 in patients with non-small cell lung cancer. Lung Cancer. 2004;46:305-312. doi:S0169500204002181 [pii] 10.1016/j. lungcan. 2004.05.003.

18. Yanagawa N, Tamura G, Oizumi H, Endoh M, Sadahiro M, Motoyama T. Inverse correlation between EGFR mutation and FHIT, RASSF1A and RUNX3 methylation in lung adenocarcinoma: relation with smoking status. Anticancer Res. 2011;31:1211-1214. doi:31/4/1211 [pii]. 
19. Egger M, Davey Smith G, Schneider M, Minder C. Bias in meta-analysis detected by a simple, graphical test. BMJ. 1997;315:629-634.

20. Benbrook D, Lernhardt E, Pfahl M. A new retinoic acid receptor identified from a hepatocellular carcinoma. Nature. 1988;333:669-672. doi:10.1038/333669a0.

21. Brand N, Petkovich M, Krust A, et al. Identification of a second human retinoic acid receptor. Nature. 1998;332:850-853. doi:10.1038/332850a0.

22. Swift CB, Hays JL, Petty WJ. Distinct functions of retinoic acid receptor beta isoforms: implications for targeted therapy. Endocr Metab Immune Disord Drug Targets. 2008;8:47-50.

23. Toulouse A, Morin J, Pelletier M, Bradley WE. Structure of the human retinoic acid receptor beta 1 gene. Biochim Biophys Acta. 1996; 1309:1-4. doi:S0167-4781(96)00126-1 [pii].

24. Ma Y, Koza-Taylor PH, DiMattia DA, et al. Microarray analysis uncovers retinoid targets in human bronchial epithelial cells. Oncogene. 2003;22:4924-4932. doi:10.1038/sj.onc.1206728 1206728 [pii].

25. Petty WJ, Li N, Biddle A, Bounds R, et al. A novel retinoic acid receptor beta isoform and retinoid resistance in lung carcinogenesis. $J$ Nat Cancer Inst. 2005;97:1645-1651. doi:97/22/1645 [pii] 10.1093/jnci/ dji371.

26. Lotan R, Xu XC, Lippman SM, et al. Suppression of retinoic acid receptor-beta in premalignant oral lesions and its up-regulation by isotretinoin. N Engl J Med. 1995;332:1405-1410. doi:10.1056/ NEJM199505253322103.

27. Peng X, Mehta RG, Tonetti DA, Christov K. Identification of novel RARbeta2 transcript variants with short 5'-UTRs in normal and cancerous breast epithelial cells. Oncogene. 2005;24:1296-1301. doi:1208284 [pii] 10.1038/sj.onc.1208284.

28. Di Croce L, Raker VA, Corsaro M, et al. Methyltransferase recruitment and DNA hypermethylation of target promoters by an oncogenic transcription factor. Science. 2002;295:1079-1082. doi:10.1126/ science. 1065173 295/5557/1079 [pii].

29. Fazi F, Zardo G, Gelmetti V, et al. Heterochromatic gene repression of the retinoic acid pathway in acute myeloid leukemia. Blood 2007;109:4432-4440. doi:blood-2006-09-045781 [pii] 10.1182/blood2006-09-045781.

30. Toulouse A, Morin J, Dion PA, Houle B, Bradley WE. RARbeta2 specificity in mediating RA inhibition of growth of lung cancer-derived cells. Lung Cancer. 2000;28:127-137. doi:S0169-5002(99)00122-1 [pii].

31. Sun SY, Wan H, Yue P, Hong WK, Lotan R. Evidence that retinoic acid receptor beta induction by retinoids is important for tumor cell growth inhibition. J Biol Chem. 2000;275:17149-17153. doi:10.1074/ jbc.M000527200 M000527200 [pii].

32. Virmani AK, Rathi A, Zöchbauer-Müller S, et al. Promoter methylation and silencing of the retinoic acid receptor-beta gene in lung carcinomas. J Natl Cancer Inst. 2000;92:1303-1307.

33. Umemura S, Fujimoto N, Hiraki A, et al. Aberrant promoter hypermethylation in serum DNA from patients with silicosis. Carcinogenesis. 2008;29:1845-1849. doi:10.1093/carcin/bgn169 bgn169 [pii].

34. Yanagawa N, Tamura G, Oizumi H, et al. Promoter hypermethylation of RASSF1A and RUNX3 genes as an independent prognostic prediction marker in surgically resected non-small cell lung cancers. Lung Cancer. 2007;58:131-138. doi:S0169-5002(07)00315-7 [pii] 10.1016/j. lungcan.2007.05.011.

35. Momparler RL, Bouffard DY, Momparler LF, Dionne J, Belanger K, Ayoub J. Pilot phase I-II study on 5-aza-2'-deoxycytidine (Decitabine) in patients with metastatic lung cancer. Anticancer Drugs. 1997;8: 358-368.

36. Tuorkey MJ. Curcumin a potent cancer preventive agent: mechanisms of cancer cell killing. Interv Med Appl Sci. 2014;6:139-146. doi:10.1556/ IMAS.6.2014.4.1 [doi] IMAS_6(2014)4/1 [pii].

37. Jiang A, Wang X, Shan X, et al. Curcumin reactivates silenced tumor suppressor gene RARbeta by reducing DNA methylation. Phytother Res. 2015;29:1237-1245. doi:10.1002/ptr.5373 [doi].
38. Hua F, Fang N, Li X, Zhu S, Zhang W, Gu J. A meta-analysis of the relationship between RARbeta gene promoter methylation and nonsmall cell lung cancer. PLoS One. 2014;9:e96163. doi:10.1371/journal. pone.0096163.

39. Kim YT, Park SJ, Lee SH, et al. Prognostic implication of aberrant promoter hypermethylation of $\mathrm{CpG}$ islands in adenocarcinoma of the lung. J Thorac Cardiovasc Surg. 2005;130:1378. doi:S0022-5223(05)01052-4 [pii] 10.1016/j.jtcvs.2005.06.015.

40. Li W, Deng J, Tang JX. Combined effects methylation of FHIT, RASSF1A and RARbeta genes on non-small cell lung cancer in the Chinese population. Asian Pac J Cancer Prev. 2014;15:5233-5237.

41. International Agency for Research on Cancer. Tobacco smoke and involuntary smoking. In IARC Monographs on the Evaluation of the Carcinogenic Risk of Chemicals to Humans. Lyon, France: International Agency for Research on Cancer, Vol 83; 2004.

42. Husgafvel-Pursiainen K. Genotoxicity of environmental tobacco smoke: a review. Mutat Res. 2004;567:427-445. doi:S1383-5742(04)00063-8 [pii] 10.1016/j.mrrev.2004.06.004 .

43. Kim YT, Lee SH, Sung SW, Kim JH. Can aberrant promoter hypermethylation of $\mathrm{CpG}$ islands predict the clinical outcome of non-small cell lung cancer after curative resection? Ann Thorac Surg. 2005;79:1180-1188; discussion. 1180-1188. doi:S0003-4975(04)02007-7 [pii] 10.1016/j. athoracsur. 2004.09.060.

44. Li W, Deng J, Wang SS, et al. Association of methylation of the RARbeta gene with cigarette smoking in non-small cell lung cancer with Southern-Central Chinese population. Asian Pac J Cancer Prev. 2014; 15:10937-10941.

45. Zhao X, Wang N, Zhang M, Xue S, Shi K, Chen Z. Detection of methylation of the RAR-beta gene in patients with non-small cell lung cancer. Oncol Lett. 2012;3:654-658. doi:10.3892/ol.2011.527 ol-03-03-0654 [pii].

46. Zhang CY, Jin YT, Xu HY, et al. [Relationship between promoter methylation of p16, DAPK and RAR beta genes and the clinical data of non-small cell lung cancer]. Zhonghua Yi Xue Yi Chuan Xue Za Zhi. 2011;28:23-28. doi:10.3760/cma.j.issn.1003-9406.2011.01.006 940628006 [pii].

47. Scesnaite A, Jarmalaite S, Mutanen P, et al. Similar DNA methylation pattern in lung tumours from smokers and never-smokers with second-hand tobacco smoke exposure. Mutagenesis. 2012;27:423-429. doi:10.1093/mutage/ger092 ger092 [pii].

48. Liu Z, Li W, Lei Z, et al. CpG island methylator phenotype involving chromosome $3 \mathrm{p}$ confers an increased risk of non-small cell lung cancer. J Thorac Oncol. 2010;5:790-797.

49. Hawes SE, Stern JE, Feng Q, et al. DNA hypermethylation of tumors from non-small cell lung cancer (NSCLC) patients is associated with gender and histologic type. Lung Cancer. 2010;69:172-179. doi:10.1016/j. lungcan.2009.11.002 S0169-5002 (09)00579-0 [pii].

50. Kubo T, Yamamoto H, Ichimura K, et al. DNA methylation in small lung adenocarcinoma with bronchioloalveolar carcinoma components. Lung Cancer. 2009;65:328-332. doi:10.1016/j.lungcan.2008.12.001 S0169-5002(08)00663-6 [pii].

51. Seng TJ, Currey N, Cooper WA, et al. DLEC1 and MLH1 promoter methylation are associated with poor prognosis in non-small cell lung carcinoma. Br J Cancer. 2008;99:375-382. doi:10.1038/sj.bjc.6604452 6604452 [pii].

52. Hsu HS, Chen TP, Wen CK, et al. Multiple genetic and epigenetic biomarkers for lung cancer detection in cytologically negative sputum and a nested case-control study for risk assessment. J Pathol. 2007;213: 412-419. doi:10.1002/path.2246.

53. Katayama H, Hiraki A, Aoe K, et al. Aberrant promoter methylation in pleural fluid DNA for diagnosis of malignant pleural effusion. Int J Cancer. 2007;120:2191-2195. doi:10.1002/ijc.22576.

54. Topaloglu O, Hoque MO, Tokumaru Y, et al. Detection of promoter hypermethylation of multiple genes in the tumor and bronchoalveolar lavage of patients with lung cancer. Clin Cancer Res. 2004;10: 2284-2288. 


\section{Publish your work in this journal}

Drug Design, Development and Therapy is an international, peerreviewed open-access journal that spans the spectrum of drug design and development through to clinical applications. Clinical outcomes, patient safety, and programs for the development and effective, safe, and sustained use of medicines are a feature of the journal, which

has also been accepted for indexing on PubMed Central. The manuscript management system is completely online and includes a very quick and fair peer-review system, which is all easy to use. Visit http://www.dovepress.com/testimonials.php to read real quotes from published authors.

Submit your manuscript here: http://www.dovepress.com/drug-design-development-and-therapy-journal 